Check for updates

Cite this: RSC Adv., 2018, 8, 4503

Received 2nd December 2017 Accepted 18th January 2018

DOI: 10.1039/c7ra12978e

rsc.li/rsc-advances

\section{In situ template synthesis of hierarchical porous carbon used for high performance lithium-sulfur batteries $\uparrow$}

\author{
Lizhen Long, (D) *a Xunyuan Jiang, ${ }^{\mathrm{b}}$ Jun Liu, ${ }^{\mathrm{a}}$ Dongmei Han, ${ }^{\text {tb }}$ Min Xiao, \\ Shuanjin Wang ${ }^{b}$ and Yuezhong Meng (D) *b
}

Hierarchical porous carbon (HPC) consists of micropores, mesopores and macrospores which are synthesized by in situ formation of template followed by acid etching. The obtained pores are threedimensional and interconnected, and evenly distributed in the carbon matrix. By adjusting the ratio of the raw materials, the high specific surface area and large pore volume is afforded. The obtained HPC-3 samples possess graphite flakes and locally graphited-carbon walls, which provide good electrical conductivity. These unique characteristics make these materials suitable cathode scaffolds for $\mathrm{Li}-\mathrm{S}$ batteries. After encapsulating $61 \%$ sulfur into HPC-3 host, the S/HPC-3 composite exhibits excellent cycling stability, high columbic efficiency, and superior rate cycling as a cathode material. The S/HPC-3 composite cathode displays an initial discharge capacity of $1059 \mathrm{~mA} \mathrm{~h} \mathrm{~g}{ }^{-1}$, and a reversible capacity of $797 \mathrm{~mA} \mathrm{~h} \mathrm{~g}^{-1}$ after 200 cycles at $0.2 \mathrm{C}$. The discharge capacities of the S/HPC-3 composite cathode after every 10 cycles at $0.1,0.2,0.5,1$, and $2 \mathrm{C}$ are $1119,1056,982,921$, and $829 \mathrm{~mA} \mathrm{~h} \mathrm{~g}^{-1}$, respectively.

\section{Introduction}

Rechargeable batteries with high energy density, long-term durability, improved safety, and in particular low cost are expected to power future portable electronic devices, electric vehicles and large-scale smart grids. ${ }^{1-3}$ Lithium-sulfur (Li-S) batteries are considered as one of the most promising candidates for next-generation rechargeable batteries due to their high theoretical specific capacity $\left(1672 \mathrm{~mA} \mathrm{~h} \mathrm{~g}^{-1}\right)$ and high energy density ( $2567 \mathrm{~W} \mathrm{~h} \mathrm{~kg}^{-1}$ ), which are nearly five times higher than those of commercially available lithium-ion

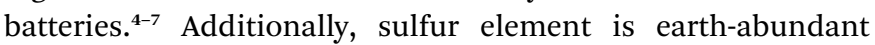
and nontoxic, and as cathode active materials can largely reduce the overall production cost. ${ }^{4,6-9}$ However, some big challenges associated with the sulfur cathode need to be solved before its large-scale commercial application. Firstly, sulfur element is a nonconductor with an electric conductivity of $5 \times$ $10^{-30} \mathrm{~S} \mathrm{~cm}^{-1}$ at $25^{\circ} \mathrm{C}^{10}$ The insulation characteristic of sulfur severely limits the sulfur utilization and influences the rate performance of lithium-sulfur batteries. ${ }^{2,11}$ Secondly, sulfur is

${ }^{a}$ College of Physics and Technology, Guangxi Normal University, Guilin 541004, P. R. China. E-mail: longlzh@foxmail.com; Fax: +86-20-84114113; Tel: +86-20-84114113 ${ }^{b}$ The Key Laboratory of Low-carbon Chemistry \& Energy Conservation of Guangdong Province, State Key Laboratory of Optoelectronic Materials and Technologies, Sun Yat-sen University, Guangzhou 510275, P. R. China. E-mail: mengyzh@mail.sysu. edu.cn; handongm@mail.sysu.edu.cn

$\dagger$ Electronic supplementary information (ESI) available. See DOI: 10.1039/c7ra12978e reduced stepwise by lithium to a sequence of lithium polysulfide intermediates $\left(\mathrm{Li}_{2} \mathrm{~S}_{n}, 3 \leq n \leq 6\right)$ during the discharge process. These intermediates are highly soluble in the organic electrolyte, and can take part in the well described "internal shuttle process", resulting in the loss of active material and low coulombic efficiency. ${ }^{12,13}$ Thirdly, the cathode suffers from significant volume variation during charge/discharge process as the result of density difference between $\mathrm{S}\left(1.96 \mathrm{~g} \mathrm{~cm}^{-3}\right)$ and $\mathrm{Li}_{2} \mathrm{~S}$ $\left(1.66 \mathrm{~g} \mathrm{~cm}^{-3}\right)$. These changes may deteriorate the electrode structure and result in capacity decay., ${ }^{4,6,9}$

In the past decades, numerous novel sulfur cathodes have been extensively explored to address the aforementioned issues, including carbon-sulfur composites (e.g., porous carbon, ${ }^{14-18}$ carbon nanotubes, ${ }^{19-21}$ carbon nanofibers, ${ }^{22,23}$ graphene ${ }^{24-26}$ and graphene oxide, ${ }^{27}$ etc.), conductive polymer-sulfur composites ${ }^{28}$ (e.g., polypyrrole (PPy), ${ }^{29,30}$ polyacrylonitrile (PAN), ${ }^{31,32}$ polyaniline (PANI), ${ }^{33,34}$ etc.), sulfur-metal oxide composites (e.g., $\mathrm{SiO}_{2}{ }^{7}$ $\mathrm{TiO}_{2},{ }^{35}$ etc.). Among these hosts, porous carbons have been proved to be effective and facile candidates due to its excellent electrical conductivity, large specific surface area, and abundant porous structure. The porous structure of the carbon matrix could effectively encapsulate sulfur and restrain the solubility of polysulfides. And their high specific surface area could provide efficient contact between sulfur and carbon for sufficient sulfur utilization. Based on their pore size, the porous carbons can be classified as microporous $(D<2 \mathrm{~nm})$, mesoporous $(2 \mathrm{~nm}<D<$ $50 \mathrm{~nm})$, and macroporous $(D>50 \mathrm{~nm})$ carbon. And each type of porous carbon possesses unique morphological advantages. The microporous and mesoporous carbon can increase the 
contact area between sulfur and carbon and provide active sites for electrochemical reaction. In addition, the microporous carbon is beneficial to trap polysulfide and lead to a stable cycling performance. But, such microporous carbon can only accommodate low sulfur content (less than $50 \mathrm{wt} \%$ ), which limits the energy density of the Li-S battery. While, the macroporous carbon can raise sulfur loading, reduce diffusive resistance to mass transport, and accommodate the volume variation during cycling process. However, carbon hosts containing macropores or mesopores with large-size would suffer from the dissolution of polysulfide, which will lead to the large capacity loss during cycling. Hierarchical porous carbon comprised of macro-, meso-, and micro-pores may achieve good electrochemical performance if well combined with sulfur due to their synergistic effects. Nazar et al. ${ }^{18}$ encapsulated up to $70 \mathrm{wt} \%$ sulfur into highly ordered channels of CMK-3 to achieving intimate contact of carbon and sulfur. And a reversible capacities up to $1000 \mathrm{~mA} \mathrm{~h} \mathrm{~g}^{-1}$ at a current rate of $0.1 \mathrm{C} \mathrm{(1C}$ $=1675 \mathrm{~mA} \mathrm{~g}^{-1}$ ) have been achieved. Xiaogang Zhang et al. ${ }^{36}$ prepare a three-dimensional (3D) hierarchically ordered porous carbon with mesoporous walls and interconnected macropores to encapsulate sulfur for high-performance $\mathrm{Li}-\mathrm{S}$ batteries. The HOPC/S with well-defined nanostructure delivers a high initial specific capacity up to $1193 \mathrm{~mA} \mathrm{~h} \mathrm{~g}^{-1}$ and a stable capacity of $884 \mathrm{~mA} \mathrm{~h} \mathrm{~g}^{-1}$ after 50 cycles at $0.1 \mathrm{C}$.

To date, the major challenge is to obtain hierarchically porous carbon with very high surface area, large pore volume and hierarchical porosity. Current synthetic methods can be categorized as hard-template, soft-template and non-template methods. ${ }^{37}$ The hard template method (nanocasting method) is the most commonly adopted method for preparing hierarchically porous carbon with well-defined pore structures and narrow pore-size distributions. ${ }^{15,38-41}$ It is generally accepted that, in this strategy, micropores and small mesopores are generated by releasing gases $\left(\mathrm{CO}_{2}, \mathrm{H}_{2} \mathrm{O}, \mathrm{CO}\right.$, etc. $)$ in the process of thermal decomposition of carbon sources, and large mesopores or macropores are replicated from hard templates. ${ }^{\mathbf{1 5 , 4 1 , 4 2}}$ Zhang et al. $^{\mathbf{4 0}}$ have synthesized HPC by using $\mathrm{Mg}(\mathrm{OH})_{2}$ as template and soluble starch as carbon source. The as-prepared HPC exhibits a relatively high specific surface area of $902.5 \mathrm{~m}^{2}$ $\mathrm{g}^{-1}$ and large total pore volume of $2.60 \mathrm{~cm}^{3} \mathrm{~g}^{-1}$. When evaluated as cathodes for Li-S batteries, the S/HPC composite exhibited superior electrochemical performance. Wang et $a l .{ }^{39}$ have prepared a series of large mesoporous carbons with hierarchical porosities using $\mathrm{CaCO}_{3}$ nanoparticles as template, formaldehyde resin as carbon precursor. By adjusting the radio of $\mathrm{CaCO}_{3}$ to formaldehyde resin, the highest BET surface area $\left(1215 \mathrm{~m}^{2}\right.$ $\left.\mathrm{g}^{-1}\right)$ and pore volume $\left(9.0 \mathrm{~cm}^{3} \mathrm{~g}^{-1}\right)$ have been obtained. Zhang et al. ${ }^{15}$ obtained a HPC material by using sucrose as the carbon source, $\mathrm{CaCO}_{3}$ as the template, and $\left(\mathrm{CH}_{3} \mathrm{COO}\right)_{2} \mathrm{Cu} \cdot \mathrm{H}_{2} \mathrm{O}$ $\left(\mathrm{Cu}(\mathrm{Ac})_{2}\right)$ as the additive. The addition of $\mathrm{Cu}(\mathrm{Ac})_{2}$ influences the carbonization process, resulting in the volume increment of small mesopores. Thus, a better utilization of sulfur is achieved and the initial discharge capacity increases from 1287 to $1397 \mathrm{~mA} \mathrm{~h} \mathrm{~g}^{-1}$. Li et al. ${ }^{41}$ have prepared mesoporous carbon (MC) spheres with hierarchical pores, controlled pore volume and high specific surface areas using sodium alginate as carbon precursor and colloidal silica particles as template. After impregnating $60 \mathrm{wt} \%$ sulfur, the obtained S/MC composite cathode material displayed a high initial discharge capacity of $1388 \mathrm{~mA} \mathrm{~h} \mathrm{~g}^{-1}$ and a good cycling stability of $857 \mathrm{~mA} \mathrm{~h} \mathrm{~g}^{-1}$ after 100 cycles at $0.2 \mathrm{C}$, and shows also excellent high rate capability.

For preparing porous carbon materials using hard-template method, the aggregation of nanoparticles is the major problem due to their high surface energy, which results in the formation of large quantities of macropores. In this paper, this problem can be effectively avoided via in situ formation of template in carbon matrix, as displayed in the process scheme in Fig. 1. In this work, water-soluble lithium citrate is used as template precursor. Sucrose and lithium citrate are both acted as carbon sources. Firstly, the lithium citrate and sucrose are dissolved together in deionized water to form a homogeneous and clear solution. Subsequently, water was gradually evaporated to make the dissolved lithium citrate recrystallize from viscous sucrose solution and finally in situ locked within the sucrose matrix. In the step of carbonization, lithium citrate is decomposed into lithium salt with uniform dimension and high dispersibility. After etching lithium salts away by acid, the HPC comprised of micropores, mesopores and macropores are obtained. The HPC samples possess graphite flakes and graphited-carbon walls, which provide good electric conductivity. The unique characteristics of high electric conductivity, high specific surface and high pore volume endow the HPC suitable cathode scaffolds for Li-S batteries.

\section{Experimental section}

\subsection{Chemicals and materials}

All reagents were of analytical grade and used as received. The trilithium citrate tetrahydrate and sucrose were purchased from Sinopharm Chemical Reagent Co., Ltd. The sodium hydroxide $(\mathrm{NaOH}, \geq 96 \%)$ and hydrochloric acid ( $\mathrm{HCl}, 36-38 \%)$ were obtained from Guangzhou Chemical Reagent Factory.

\subsection{Synthesis of hierarchically porous carbon (HPC)}

HPC samples were prepared by in situ formation of template followed by acid etching strategy. Water-soluble lithium citrate is used as template precursor. Sucrose and lithium citrate are both acted as carbon sources. The preparation process is as follows: firstly, $1 \mathrm{~g}$ of sucrose and a certain amount of trilithium citrate tetrahydrate (sucrose $:$ trilithium citrate tetrahydrate $=$ $1: 0.77,1: 1.54,1: 2.31$, and $1: 3.08$, denoted as HPC-1, HPC-2, HPC-3 and HPC-4, respectively) were dissolved in $50 \mathrm{ml}$ deionized water together with $0.1 \mathrm{ml}$ of $2.5 \mathrm{M} \mathrm{NaOH}$ aqueous solution to form a homogeneous solution. Secondly, the deionized water was removed by vacuum-rotary evaporation method to obtain a sticky mixture. Thirdly, the mixture was placed in a $100{ }^{\circ} \mathrm{C}$ vacuum oven for $3 \mathrm{~h}$ and then $160{ }^{\circ} \mathrm{C}$ for $6 \mathrm{~h}$ to get a brown product. Subsequently, the brown product was carbonized in a tubular furnace under $\mathrm{N}_{2}$ flow at room temperature to $950{ }^{\circ} \mathrm{C}$ at $5{ }^{\circ} \mathrm{C} \mathrm{min}^{-1}$. The salts obtained from the carbonization of trilithium citrate tetrahydrate were characterized to be $\mathrm{Li}_{2} \mathrm{CO}_{3}$, as confirmed by the XRD pattern of HPC-3 before acid- 


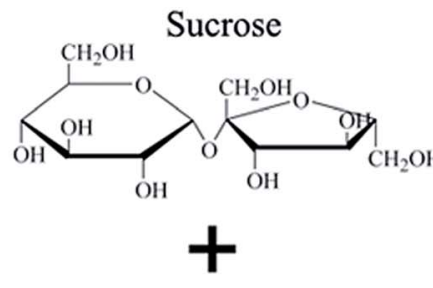

Trilithium citrate tetrahydrate<smiles>O=C(O)CC(O)(CC(=O)O)C(=O)O</smiles>

\section{HPC}

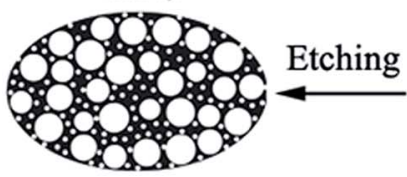

Carbon $\mathrm{Li}_{2} \mathrm{CO}_{3}$

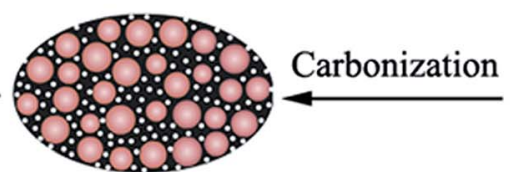

Lithium citrate
Dissolve in deionized water

Clear solution

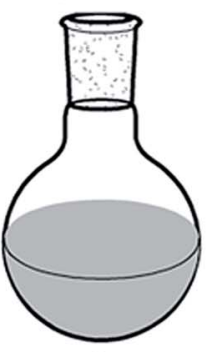

Water removal

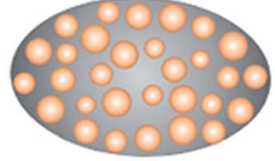

Sucrose

Fig. 1 Schematic drawing for the synthesis of HPC by in situ formation of template in carbon matrix.

treatment, (see Fig. S1†). As shown in SEM images of Fig. S2, $\dagger$ the $\mathrm{Li}_{2} \mathrm{CO}_{3}$ salts (white dots) are dispersed in carbon matrix with uniform dimensions and high dispersibility. Finally, the $\mathrm{Li}_{2} \mathrm{CO}_{3}$ templates were etched away by $2 \mathrm{M}$ hydrochloric acid to obtain the HPC samples. Thermal gravimetric analysis confirmed that $\mathrm{Li}_{2} \mathrm{CO}_{3}$ salts are completely etched away for all HPC samples, as shown in Fig. S3. $\dagger$

\subsection{Synthesis of S/HPC-3 composite}

Due to the highest specific surface area and largest pore volume among the four samples, the HPC-3 is chosen as the host for encapsulating sulfur to prepare cathode materials. The S/HPC-3 composite was prepared following the typical melt-diffusion strategy. The HPC-3 and sulfur with a weight ratio of $1: 2$ were ground together and heated in a tube furnace at $155{ }^{\circ} \mathrm{C}$ for $12 \mathrm{~h}$ followed by another $2 \mathrm{~h}$ at $220^{\circ} \mathrm{C}$ under $\mathrm{N}_{2}$ protection. After cooling down to room temperature, the S/HPC-3 composite was obtained.

\subsection{Materials characterization}

$\mathrm{N}_{2}$ adsorption/desorption analysis was performed on a Micromeritics ASAP 2460 analyzer at $-196{ }^{\circ} \mathrm{C}$ using nitrogen. Electron conductivity was measured on a semiconductor powder electron conductivity test board (Suzhou Jingle Electronic Co., Ltd., SZT-D) at ambient temperature using the four-contact method. Thermogravimetric analysis (TGA) was conducted on PerkinElmer Pyris Diamond TG/DTA thermal analyzer. The X-ray diffraction (XRD) was operated at $40 \mathrm{kV}$ and $40 \mathrm{~mA}$ by a D/Max-IIIA Powder $\mathrm{X}$-ray diffractometer and using $\mathrm{Cu}-\mathrm{K} \alpha$ radiation $(\lambda=0.15406 \mathrm{~nm})$. Raman spectra were recorded using a Renishaw inVia Raman spectrophotometer with a He-Ne laser excitation at $633 \mathrm{~nm}$. The morphology of the samples was examined by a field emission environment scanning electron microscope (SEM, Quanta 400F) and transmission electron microscopy (TEM, FEI Tecnai G2 F30) with an acceleration voltage of $300 \mathrm{kV}$. An energy dispersive spectrometers (EDS) attached to the TEM apparatus was used for microscopic elemental analysis.

\subsection{Electrode preparation and electrochemical measurements}

Cathode from the S/HPC-3 composite was prepared by a slurry coating procedure. The S/HPC-3 composite was mixed with super-P and polyvinylidene fluoride (PVDF) in a weight ratio of 90 (composite) : 2 (super P) : 8 (binder), and $N$-methylpyrrolidinone (NMP) was added to form homogeneous slurries. After ball-milling at a rotate speed of $160 \mathrm{rpm}$ for $24 \mathrm{~h}$, the slurries were cast onto the carbon-coated aluminum foil using the doctor blade method and dried at $60^{\circ} \mathrm{C}$ overnight. Then, the electrodes were punched into $12 \mathrm{~mm}$ circular discs and the sulfur loading was calculated to be about $2.0 \mathrm{mg} \mathrm{cm}^{-2}$. For comparison, the pure sulfur electrode, was prepared by the same procedure but based on sulfur, super $\mathrm{P}$, and PVDF in a mass ratio of $60: 32: 8$. CR2025 coin-type half-cells were assembled in an argon-filled glove box (Mikrouna super 1220/ 750). $1 \mathrm{M}$ lithium bis(trifluoromethane sulfonyl)imide (LiTFSI) in 1,3-dioxolane (DOL) and 1,2-dimethoxymethane (DME) (1: 1 $=\mathrm{v} / \mathrm{v}$ ) containing $2 \mathrm{wt} \% \mathrm{LiNO}_{3}$ was used as the electrolyte. The amount of the electrolyte in the cell is $50 \mu \mathrm{l}$. Lithium metal was used as the counter electrode and a microporous polyethylene membrane (Celgard 2500) was used as separator.

Galvanostatic charge-discharge tests were performed using a CT2001ALand Battery Testing System in the potential range of 1.7-2.8 V versus $\mathrm{Li} / \mathrm{Li}^{+}$at different current densities. All specific capacity values were calculated on the basis of sulfur mass. Cyclic voltammetry (CV) measurements were carried out using an S1287 electrochemical interface (Solartron) in the potential 
range of 1.7 to $2.7 \mathrm{~V}$ versus $\mathrm{Li} / \mathrm{Li}^{+}$with a scan rate of $0.2 \mathrm{mV} \mathrm{s}^{-1}$. Electrochemical impedance spectroscopy (EIS) was recorded on an electrochemical working station PCI4/300 (Gamry Instrument, Warminster, PA, USA) in the range of $1 \mathrm{MHz}$ to $0.01 \mathrm{~Hz}$ with a disturbance amplitude of $5 \mathrm{mV}$. All electrochemical tests were conducted at room temperature.

\section{Results and discussion}

Fig. 2 shows the typical nitrogen (77 K) adsorption/desorption isotherm and pore-size distribution curves of the HPC samples. The isotherms for all samples exhibit typically type IV isotherms according to the IUPAC classification (see Fig. 2(a)). ${ }^{43}$ The sharp $\mathrm{N}_{2}$ uptake at low pressure $\left(P / P_{0}<0.1\right)$ for HPC samples indicates the existence of abundant micropores. ${ }^{44}$ The samples also show a type- $\mathrm{H}_{1}$ hysteresis hoop at the range of 0.45-1.0 and obvious capillary condensation steps, suggesting the existence of a pore size range from mesoporous to macropores. ${ }^{41,45}$ The pore size distribution plots were derived from the adsorption branch of the isotherm based on the density functional theory (DFT). The HPC samples contain abundant micropores, mesopores and macroporous (see Fig. 2(b and c)), indicating that the obtained HPC samples possessed a hierarchical pore structure.

The detailed pore parameters for the HPCs are listed in Table 1. The specific surface area was calculated using the Brunauer-
Table 1 Porosity parameters of HPC samples

\begin{tabular}{lllllll}
\hline & & & \multicolumn{3}{c}{ Pore volume $\left(\mathrm{cm}^{3} \mathrm{~g}^{-1}\right)$} \\
\cline { 4 - 7 } Sample & $\begin{array}{l}\text { Sucrose : lithium } \\
\text { citrate }(\mathrm{wt} \%)\end{array}$ & $S_{\text {BET }}\left(\mathrm{m}^{2} \mathrm{~g}^{-1}\right)$ & $V_{\mathrm{t}}$ & $V_{\text {mic }}$ & $V_{\text {mes\&mac }}$ \\
\hline HPC-1 & $1: 0.77$ & 412 & 0.62 & 0.26 & 0.36 \\
HPC-2 & $1: 1.54$ & 708 & 1.08 & 0.34 & 0.74 \\
HPC-3 & $1: 2.31$ & 991 & 1.50 & 0.34 & 1.16 \\
HPC-4 & $1: 3.08$ & 289 & 1.26 & 0.06 & 1.20
\end{tabular}

Emmett-Teller (BET) method based on adsorption data in the partial pressure $\left(P / P_{0}\right)$ range of $0.08-0.30$, and the total pore volume was determined from the amount of nitrogen adsorbed at $P / P_{0}=0.99$. As the weight ratio of trilithium citrate tetrahydrate to sucrose increases, the BET surface area and the total pore volume of HPCs increase and reach to the maximum value of $991 \mathrm{~m}^{2} \mathrm{~g}^{-1}$ and $1.50 \mathrm{~cm}^{3} \mathrm{~g}^{-1}$, respectively, at $1: 2.31$. Because the mesopores and macropores in HPCs are created by removing $\mathrm{Li}_{2} \mathrm{CO}_{3}$ nanoparticles, the mesopore and macropore volume increases drastically with the increase of trilithium citrate tetrahydrate, and contributing more than $77.3 \%$ of the total pore volume for HPC-3 sample. The micropore volume is almost independent of the change of trilithium citrate tetrahydrate, further confirmed that the gases (such as $\mathrm{CO}_{2}, \mathrm{H}_{2} \mathrm{O}$, $\mathrm{CO}$ ) released from the pyrolysis of the sucrose is responsible for the formation of micropores.
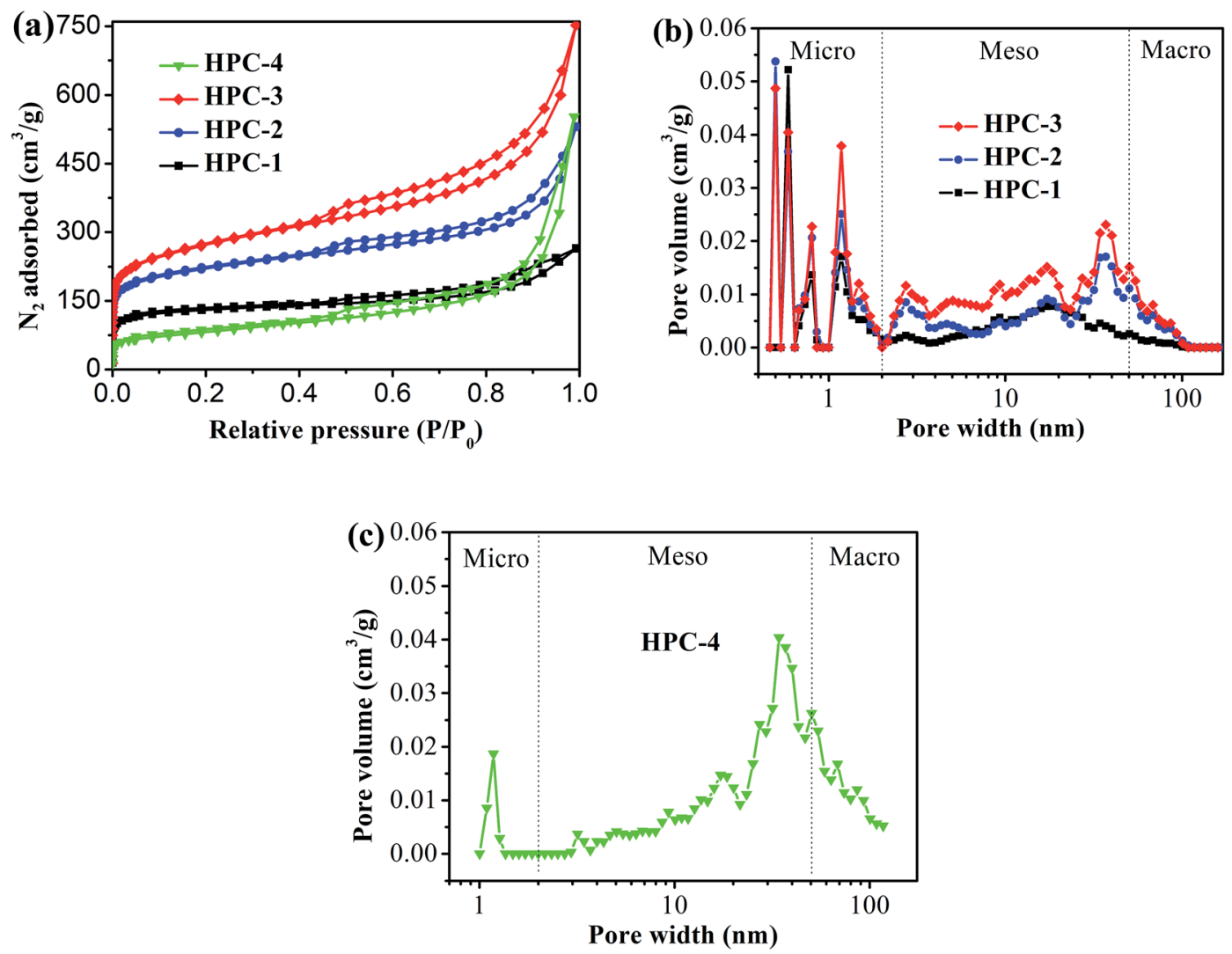

Fig. 2 (a) Nitrogen adsorption/desorption isotherm of HPC samples, and pore-size distribution curves of (b) HPC-1, HPC-2 and HPC-3, and (c) HPC-4. 
Due to the highest $S_{\mathrm{BET}}$ and the largest total pore volume, the as-prepared HPC-3 sample was chosen as the host to encapsulate sulfur for preparing cathode materials. Considering volume expansion, the theoretical amount of sulfur that HPC-3 can accommodate was calculated according to the following method: the loading amount of sulfur $=$ weight of the HPC $\times$ total pore volume $\times$ density of lithium sulfide $\left(1.66 \mathrm{~g} \mathrm{~cm}^{-3}\right) \times$ the weight ratio of sulfur in lithium sulfide $(69.78 \%) .{ }^{18}$ Based on the total pore volume of HPC-3 $\left(1.50 \mathrm{~cm}^{3} \mathrm{~g}^{-1}\right)$, the theoretical amount of sulfur is calculated to be $63.3 \mathrm{wt} \%$. Measured by the thermal gravimetric analysis (TGA), the sulfur content in the $\mathrm{S} /$ HPC-3 composite is actually about $61 \mathrm{wt} \%$, as shown in Fig. 3(a), less than the theoretical limit of $63.3 \mathrm{wt} \%$. The pore-size distribution curve of S/HPC-3 composite is displayed in Fig. 3(b). After encapsulating sulfur into hierarchical pores, the $S_{\mathrm{BET}}$ and total pore volume of S/HPC-3 composite decreased to $14 \mathrm{~m}^{2} \mathrm{~g}^{-1}$ and $0.16 \mathrm{~cm}^{3} \mathrm{~g}^{-1}$, respectively. The micropores are disappeared, further confirmed that the molten sulfur was accommodated into the pores of HPC-3 via capillary force. ${ }^{46} \mathrm{~A}$ portion of mesopores and macroporesis still available for $\mathrm{S} /$ HPC-3, which can help buffering volume expansion, allowing the accessibility of the electrolyte and fast transport of $\mathrm{Li}^{+}$ during cycling process. XRD patterns for HPC-3 and S/HPC-3 composite are illustrated in Fig. 3(c). The broad diffraction peaks around $23^{\circ}$ and a weak peaks at $44^{\circ}$ are observed in the pattern of HPC-3, indicating an amorphous state of carbon. ${ }^{41}$ The S/HPC-3 composite exhibits only one broad diffraction peak at $23^{\circ}$, and no diffraction peaks of the crystalline sulfur were observed, indicating that sulfur is confined in the internal pores. $^{41,47}$
Field-emission scanning electron microscopy (SEM) was used to examine the morphology of the HPC-3 and S/HPC-3 composite. As shown in Fig. 4(a), the HPC-3 samples exhibit highly developed porous structure, and the pores are threedimensional and interconnected. Large mesopores or macropores are evenly distributed in carbon matrix, which is attributable to the in situ formation of $\mathrm{Li}_{2} \mathrm{CO}_{3}$ templates in carbon host during preparation. The special pore structure could favor for the sulfur encapsulation. After loading 61\% sulfur, a portion of macropores are still observed from S/HPC-3 composite, as shown in Fig. 4(b), which can provide space for electrolyte ingress and fast $\mathrm{Li}^{+}$transportation during cycling. Sulfur nanoparticles are locked in the inner pores of HPC-3, and no large bulk sulfur could be observed on the surface due to its high specific surface area and high pore volume. The elemental mapping images of carbon (Fig. 4(d)) and sulfur (Fig. 4(e)) corresponding to the area outlined by the magenta square in SEM image of S/HPC-3 (Fig. 4(c)) clearly demonstrate that sulfur has a highly dispersed state in HPC-3, which in accordance with the XRD results.

To further observe the morphology of the HPC-3 and S/HPC3 composites, TEM measurements were introduced. As presented in Fig. 5(a), the HPC-3 sample consists of threedimensionally interconnected pore structure and some laminated structures (marked with white arrows). The HRTEM image of the laminated structure (Fig. 5(b)) shows clear crystal plane with an interplanar distance of $0.34 \mathrm{~nm}$, which is corresponds to the graphite (002) crystal plane. The similar graphite structures are also reported by Klose et al. who synthesized carbon materials by carbonizing iron-containing metal-organic
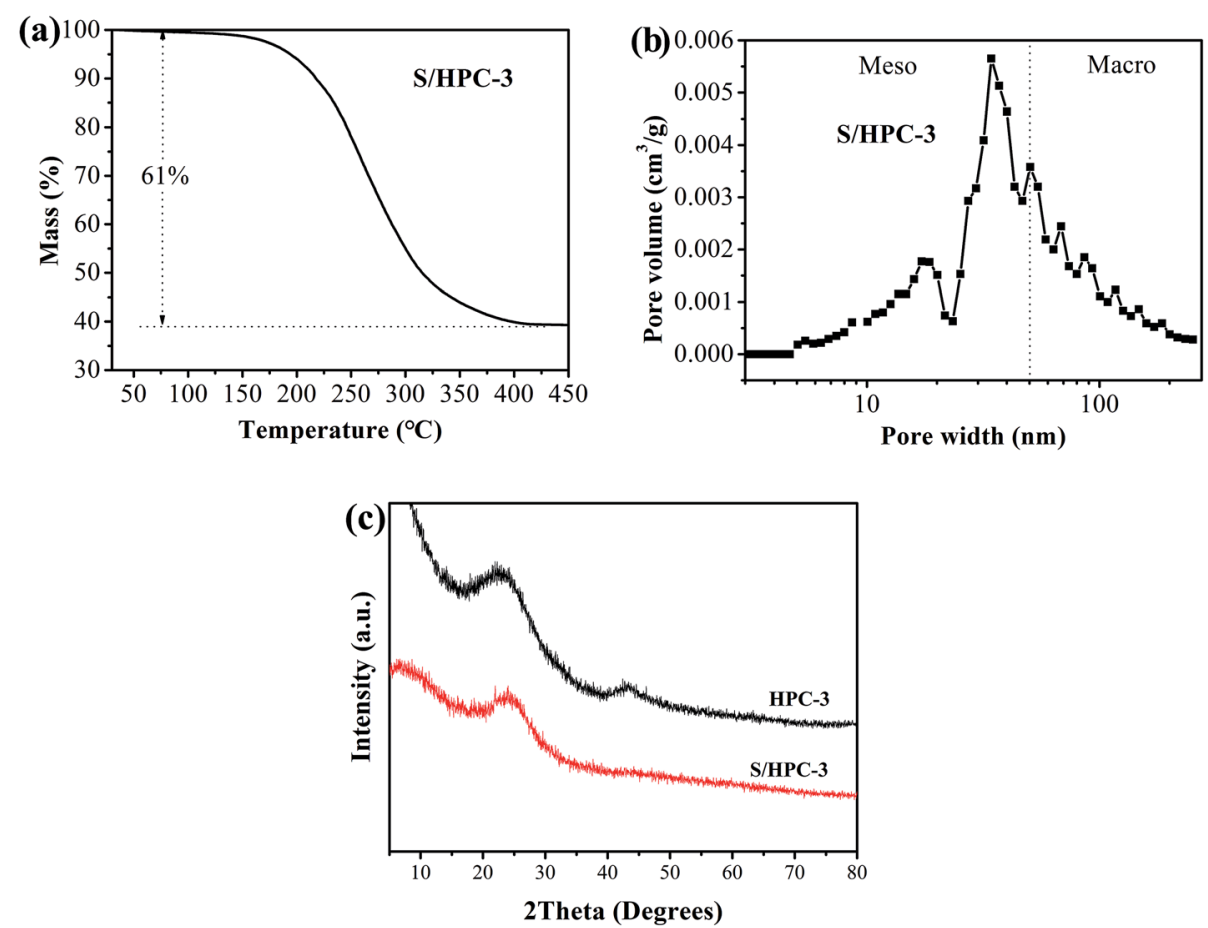

Fig. 3 (a) Thermogravimetric curve of S/HPC-3 sample in $\mathrm{N}_{2}$, (b) pore-size distribution curve of S/HPC-3 composite, and (c) XRD patterns of HPC-3 and S/HPC-3 composite. 

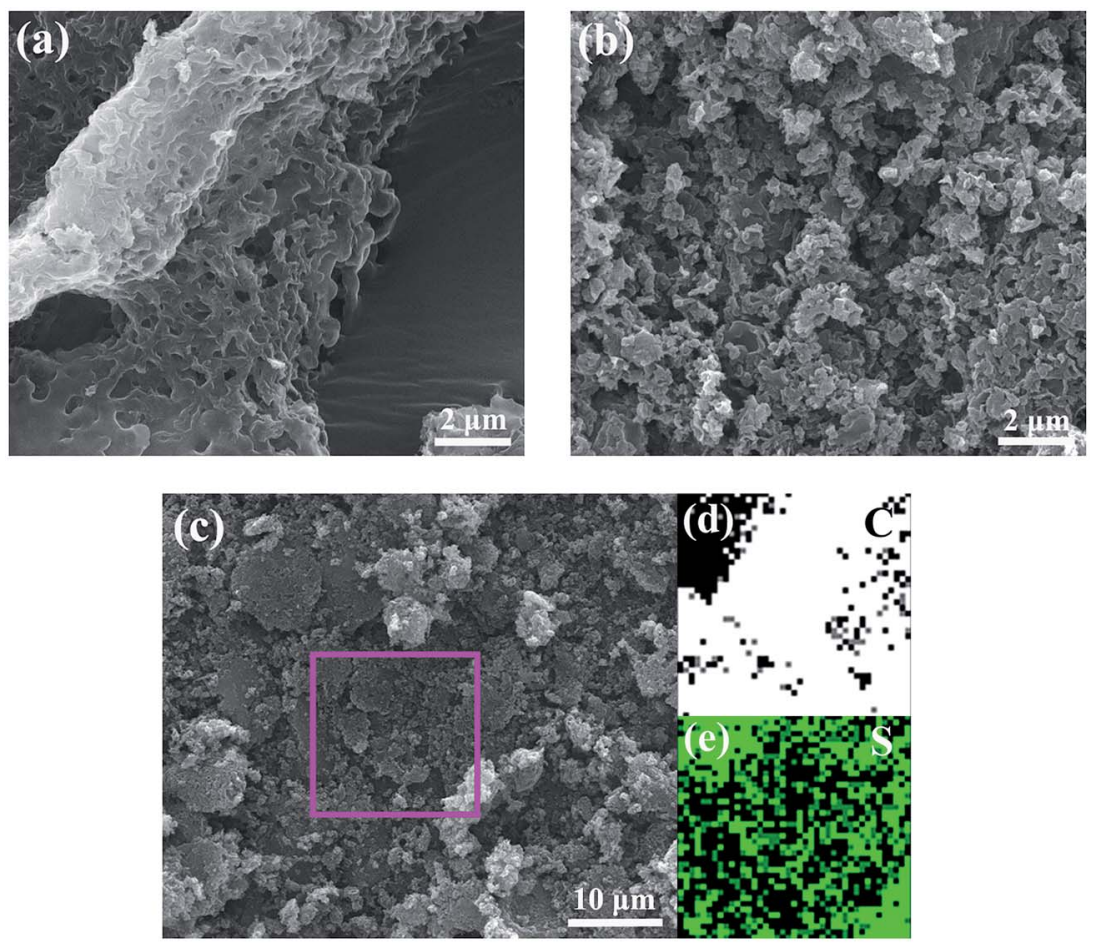

Fig. 4 SEM image of (a) HPC-3 and (b) S/HPC-3, elemental mappings of (d) carbon and (e) sulfur corresponding to the area outlined by the magenta square in SEM image of (c) S/HPC-3.

framework..$^{48}$ The HRTEM image of HPC-3 (Fig. 5(c)) further shows that most of these pores are irregular and the thicknesses of carbon walls are less than $4 \mathrm{~nm}$. The carbon walls are consisted of localized graphitic structures and amorphous components. The space between two distorted lattice fringes is $0.34 \mathrm{~nm}$, which is consistent with the (002) plane of partially graphitized HPC-3. ${ }^{49}$ These graphite flakes and localized graphited-carbon walls are both beneficial for electronic transmission. The carbon material and sulfur are both hydrophobic, and thus available for the ready absorption of sulfur into the pores through capillary forces. As displayed in Fig. 5(d), the sulfur nanoparticles (black dots) are evenly distributed in carbon host without any agglomerations of bulk sulfur on the surface, indicating the full incorporation of sulfur into the pores. This result is corresponding to the previous XRD, SEM, and nitrogen adsorption/desorption results, which strongly confirmed that the sulfur is completely encapsulated in the pores of HPC-3. As shown in HRTEM image of Fig. 5(e), the S/ HPC-3 composite still remains the graphited-carbon walls. The highly dispersed sulfur encapsulated into the hierarchical pores of HPC-3 can generate intimate contact with interconnected carbon framework, giving rise to a short pathway for transport of both $\mathrm{Li}^{+}$and electrons.

Raman spectroscopy is a very useful tool to study the microstructure of carbon in composite material. Fig. 6(a) compares the Raman spectrum of the pristine sulfur, HPC-3 and S/HPC-3 composites. For HPC-3 sample, two intense broad bands located at 1328 and $1587 \mathrm{~cm}^{-1}$ are attributed to the carbon defects (D-band) and the in-plane vibration of $\mathrm{sp}^{2}$ carbon atoms (G-band), respectively. ${ }^{50}$ The coexistence of two bands indicates that the carbon is partially graphitized with some defects and disorders. The calculated integral intensity ratios $\left(I_{\mathrm{D}} / I_{\mathrm{G}}\right)$ is a useful index for comparing the degree of crystallinity of various carbon materials. ${ }^{49} \mathrm{In}$ terms of the integral areas, we can calculate the $I_{\mathrm{D}} / I_{\mathrm{G}}$ ratio of the HPC-3 sample to be about 3.01. Compared with HPC-3, the $I_{\mathrm{D}} / I_{\mathrm{G}}$ ratio of $\mathrm{S} /$ HPC-3 composite is slightly increased to 3.37 , suggesting more lattice defects, which arise from the merging of sulfur atoms into the HPC-3 lattice. ${ }^{43}$ Furthermore, Raman spectra of S/HPC-3 exhibits no characteristic peaks of elemental sulfur in the region of $60-500 \mathrm{~cm}^{-1}$, which are related to vibration of the $\mathrm{S}-\mathrm{S}$ bond in $\mathrm{S}_{8}$ species. ${ }^{51}$ This phenomenon suggested that sulfur is successfully impregnated into pores and adsorbed on the internal surface of HPC-3 host, which is in good accordance with the XRD and $\mathrm{N}_{2}$ adsorption/desorption results.

To further confirm the microstructures and investigate the changes before and after sulfur encapsulating, the electronic conductivity of HPC samples and S/HPC-3 composite were tested by the four-probe method. The samples were loaded in a Teflon cylinder with an inner diameter of $16 \mathrm{~mm}$, and two stainless steel plungers were used to deliver pressure through a hydraulic press device. The voltage and current through stainless-steel plungers were recorded by using two Keithley 2000 digital multimeters. The electrical conductivity was calculated on the basis of the powder electrical resistivity. Fig. 6(b) shows the conductivity values of HPC and S/HPC-3 samples at the pressure range of 4-20 MPa, respectively. In a control experiment, the electronic conductivity of Super P is 

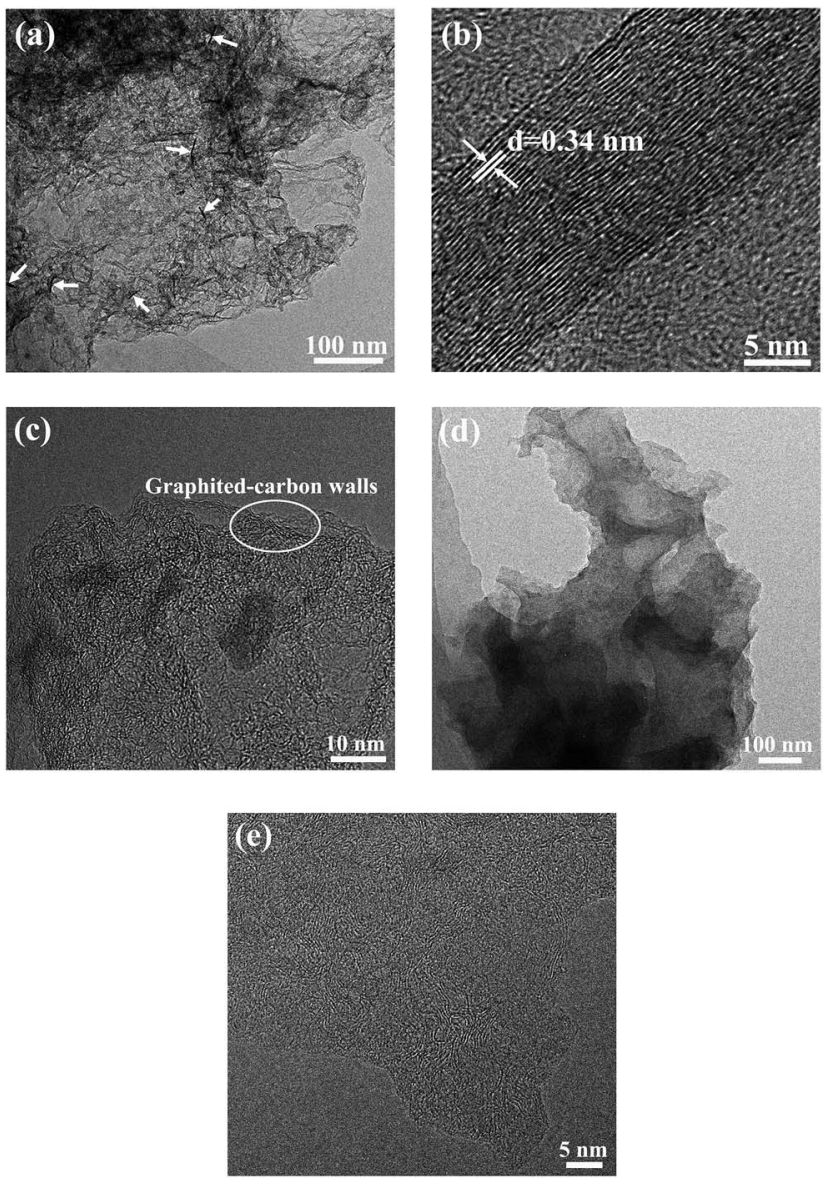

Fig. 5 TEM images of (a) HPC-3 and (d) S/HPC-3, HRTEM images of (b) graphite structure, (c) HPC-3 and (e) S/HPC-3.

also measured. The electronic conductivity is slightly higher for Super $\mathrm{P}$ when the applied pressure is less than $9 \mathrm{MPa}$. But with the pressure increase to $20 \mathrm{MPa}$, the electronic conductivity for HPC-3 is dramatically increased and reach to the maximum value of $105.7 \mathrm{~S} \mathrm{~cm}^{-1}$, which is more than two times higher than that of Super P (41.5 S cm $\left.\mathrm{cm}^{-1}\right)$. The high conductivity of HPC-3 at high pressure is related to the formation of graphitic and porous structure, which is confirmed by SEM, HRTEM and Raman spectroscopy. The electrical conductivity of the S/HPC-3 composite is lower than HPC-3, which is ascribed to the encapsulated sulfur. The comparison between the electrical conductivity of HPC samples and super $\mathrm{P}$ are also shown in Fig. S4. $\dagger$

CR2025 coin-type half-cells using lithium foils as the anode and the S/HPC-3 composite as the cathode were assembled to investigate the electrochemical properties. For comparison, the performance of the pure S cathode with $60 \mathrm{wt} \%$ sulfur content was also evaluated in the same conditions. Fig. 7(a) and (b) presents the cyclic voltammogram (CV) curves of the S/HPC-3 composite and pure $\mathrm{S}$ cathode in the voltage range of $1.7-2.7 \mathrm{~V}$ with a scan rate of $0.2 \mathrm{mV} \mathrm{s}^{-1}$, respectively. For S/HPC-3 composite cathode, two typical reduction (cathodic) peaks at approximately $2.29 \mathrm{~V}$ and $2.01 \mathrm{~V}$ were observed, corresponding to the reduction of sulfur to long-chain lithium polysulfides $\left(\mathrm{Li}_{2} \mathrm{~S}_{n}, 4 \leq n \leq 8\right)$ and further reduction to $\mathrm{Li}_{2} \mathrm{~S}_{2}$ and eventually to $\mathrm{Li}_{2} \mathrm{~S}$, respectively. ${ }^{52,53}$ One oxidation peak (anodic) at about $2.44 \mathrm{~V}$ with shoulder at $2.47 \mathrm{~V}$ are attributed to the oxidization of solid $\mathrm{Li}_{2} \mathrm{~S}$ and $\mathrm{Li}_{2} \mathrm{~S}_{2}$ to lithium polysulfides and further conversion to element sulfur, respectively. ${ }^{54,55}$ After the first two cycles, the oxide peak splits into two peaks and gradually shift to lower potentials, and no distinct current changes for cathodic peaks, indicating a high degree of reactive reversibility and electrochemical stability of the S/HPC-3 cathode. ${ }^{49}$ Compared to pure $\mathrm{S}$, the S/HPC-3 composite had a higher reduction peak current and oxidation peak current indicate that the S/HPC-3 composite had a higher charge/discharge capacity. In addition, the potential difference between the reduction and oxidation current peaks $(\Delta E)$ is an indicative of electrochemical polarization. The S/HPC3 composite displayed a smaller $\Delta E$ than the pure $\mathrm{S}$ cathode, indicating a smaller electrochemical polarization. The large surface area and high pore volume of HPC-3 provide more reactive sites and unobstructed transport channels for $\mathrm{Li}^{+}$and electrolyte, which can lower the electrochemical polarization and improves the utilization of sulfur (more capacity output). ${ }^{53}$

Fig. 8 is the Nyquist plots of S/HPC-3 composite and pure S. The intercept at the real axis resistance is corresponding to the combined resistance $\left(R_{\mathrm{ohm}}\right)$, which is determined by the ionic resistance of the electrolyte, the intrinsic resistance of the active materials, and the contact resistance at the active material/ current interface. ${ }^{15,36}$ The depressed semicircle in the highfrequency region is corresponding to the charge-transfer resistance $\left(R_{\mathrm{ct}}\right)$ through the electrode-electrolyte interface. The short inclined lines in the low frequency region are associated with
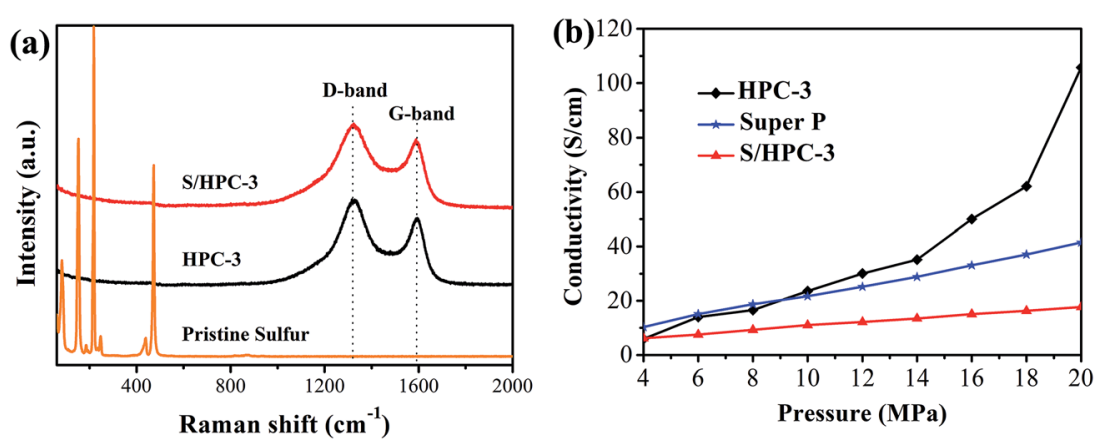

Fig. 6 (a) Raman spectra of pristine sulfur, HPC-3 and S/HPC-3, and (b) electronic conductivity of HPC-3, S/HPC-3 composite and super P. 

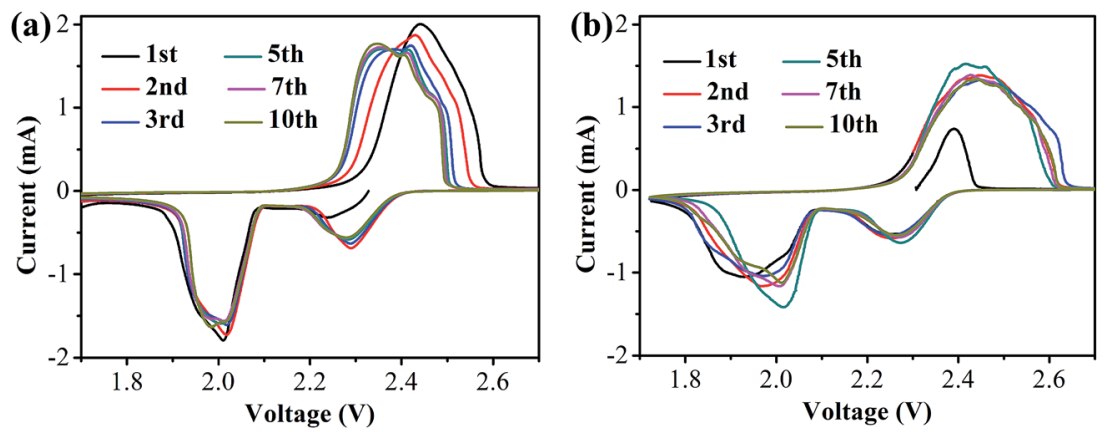

Fig. 7 The CV curves of (a) S/HPC-3 and (b) pure sulfur cathode during the first 10 cycles.

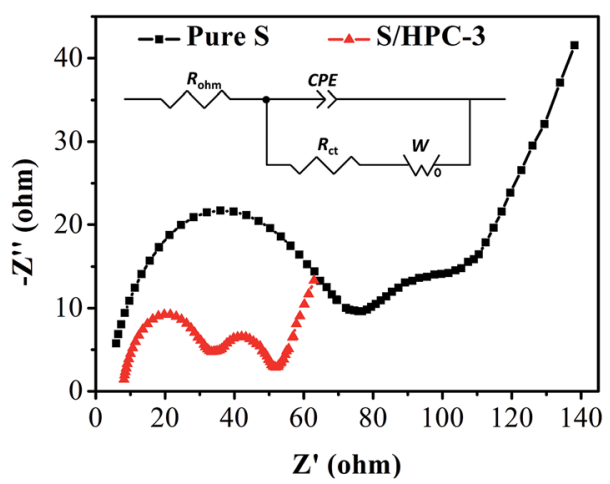

Fig. 8 Electrochemical impedance spectrum of S/HPC-3 and pure sulfur in lithium/sulfur batteries before initial discharge.

a semi-infinite Warburg diffusion process of soluble lithium polysulfide in the electrolyte. ${ }^{15,36}$ It is obvious that the S/HPC-3 composite cathode shows a much smaller $R_{\mathrm{ct}}$ value $(29 \Omega)$ than pure S cathode $(87 \Omega$ ), suggesting a lower charge-transfer resistance of composite cathode. Combining the results of CV, electric conductivity and BET, we speculate that the close contact between sulfur and the carbon host in the S/HPC-3 composite, and high electric conductivity of carbon host might be the reasons for the smaller $R_{\mathrm{ct}}$.

Fig. 9(a) and (b) show the galvanostatic discharge/charge curves with S/HPC-3 composite and pure sulfur cathodes in the 1st, 10th, 25th, 50th, 100th and 200th cycles at $0.2 \mathrm{C}(1 \mathrm{C}=$ $1675 \mathrm{~mA} \mathrm{~g}^{-1}$ ) between $1.7 \mathrm{~V}$ and $2.8 \mathrm{~V}$. All capacity values in this article are calculated on the basis of sulfur mass. Consistent with the CV results, the discharge voltage profiles of the two samples exhibit two typical discharge plateaus at around $2.34 \mathrm{~V}$ and $2.1 \mathrm{~V}$, corresponding to the formation of high order polysulfide and $\mathrm{Li}_{2} \mathrm{~S}_{2} / \mathrm{Li}_{2} \mathrm{~S}$, respectively. In order to reveal the overall electrochemical performance, the cyclic stability of S/HPC-3 composite and pure sulfur cathode was investigated, as shown in Fig. 9(c). The S/HPC-3 composite demonstrates a higher initial discharge capacity of $1059 \mathrm{~mA} \mathrm{~h} \mathrm{~g}^{-1}$ than that of pure sulfur cathode $\left(640 \mathrm{~mA} \mathrm{~h} \mathrm{~g}^{-1}\right)$ at a current density of $0.2 \mathrm{C}$. Both composites show a rapid capacity loss in the beginning 30 cycles due to unavoidable dissolution of polysulfides into the electrolytes. In the following cycles, S/HPC-3 composite exhibits a relatively stable charge-discharge process. After 200 cycles, the S/HPC-3 composite still remains a capacity of $797 \mathrm{~mA} \mathrm{~h} \mathrm{~g}^{-1}$, much higher that of pure sulfur cathode $\left(365 \mathrm{~mA} \mathrm{~h} \mathrm{~g}^{-1}\right)$. The decay rate of S/HPC-3 and pure sulfur cathode is calculated to be $0.12 \%$ and $0.21 \%$ per cycle, respectively. To further investigate the high rate and long cycling life of the S/HPC-3 composite, a prolonged cycling test was conducted at a current density of 0.5C. As shown in Fig. 9(d), an initial discharge capacity of $975 \mathrm{~mA} \mathrm{~h} \mathrm{~g}^{-1}$ is delivered, and after 200 cycles, a discharge capacity of $735 \mathrm{~mA} \mathrm{~h} \mathrm{~g}^{-1}$ is still preserved on the S/HPC-3 composite cathode. The decay rate is $0.12 \%$ of initial capacity per cycle, thus exhibiting outstanding cycling stability and high capacity. The coulombic efficiency remains around $98.7 \%$ over the 200 cycles, thus indicating the very small impact of the shuttle effect of polysulfides. The higher discharge capacity and better cycling performance of S/HPC-3 could be attributed to its unique hierarchical porous structure available after sulfur loading and buffer volume expansion during cycling.

Fig. 9(e) exhibits the representative discharge-charge curves with S/HPC-3 composite cathode at various current rates. The discharge capacities at $0.1,0.2,0.5,1$, and $2 \mathrm{C}$ are 1119,1056 , 982, 921, and $829 \mathrm{~mA} \mathrm{~h} \mathrm{~g}^{-1}$, in their turns. It is noticeable that, with increasing current density, the space between the charge and discharge plateaus are enlarged. This phenomenon is due to the kinetic effects of the material, rendering a large polarization. ${ }^{56}$ Fig. 9(f) displays the rate capabilities of the S/HPC-3 composite electrode from $0.1 \mathrm{C}$ to $2 \mathrm{C}$. The discharge capacities maintain stable and reduce regularly with the increase of current rate. After every 10 cycles at a specific current rate, the capacities retention at $0.1,0.2,0.5,1$ and $2 \mathrm{C}$ are about $100.8 \%, 98.6 \%$, $99.7 \%$ and $96.4 \%$ of the initial discharge capacities, implying an excellent rate cycling of the S/HPC-3 composite electrode. When the current density return to $0.1 \mathrm{C}$, the discharge capacity can be recovered, which is $1060 \mathrm{~mA} \mathrm{~h} \mathrm{~g}{ }^{-1}$. These results demonstrate that the S/HPC-3 composite electrode has good electrochemical reversibility and structural stability.

Based on the above results, the excellent electrochemical performance of S/HPC-3 composite cathodes can be attributed to the following two reasons: (1) the synergistic advantages of hierarchical porous structure. The macropores and large mesopores accommodate a high sulfur loading, provide unobstructed transport channels for $\mathrm{Li}^{+}$and electrolyte, and accommodate the volume variation during charge/discharge process, leading to high discharge capacity and better cycling 

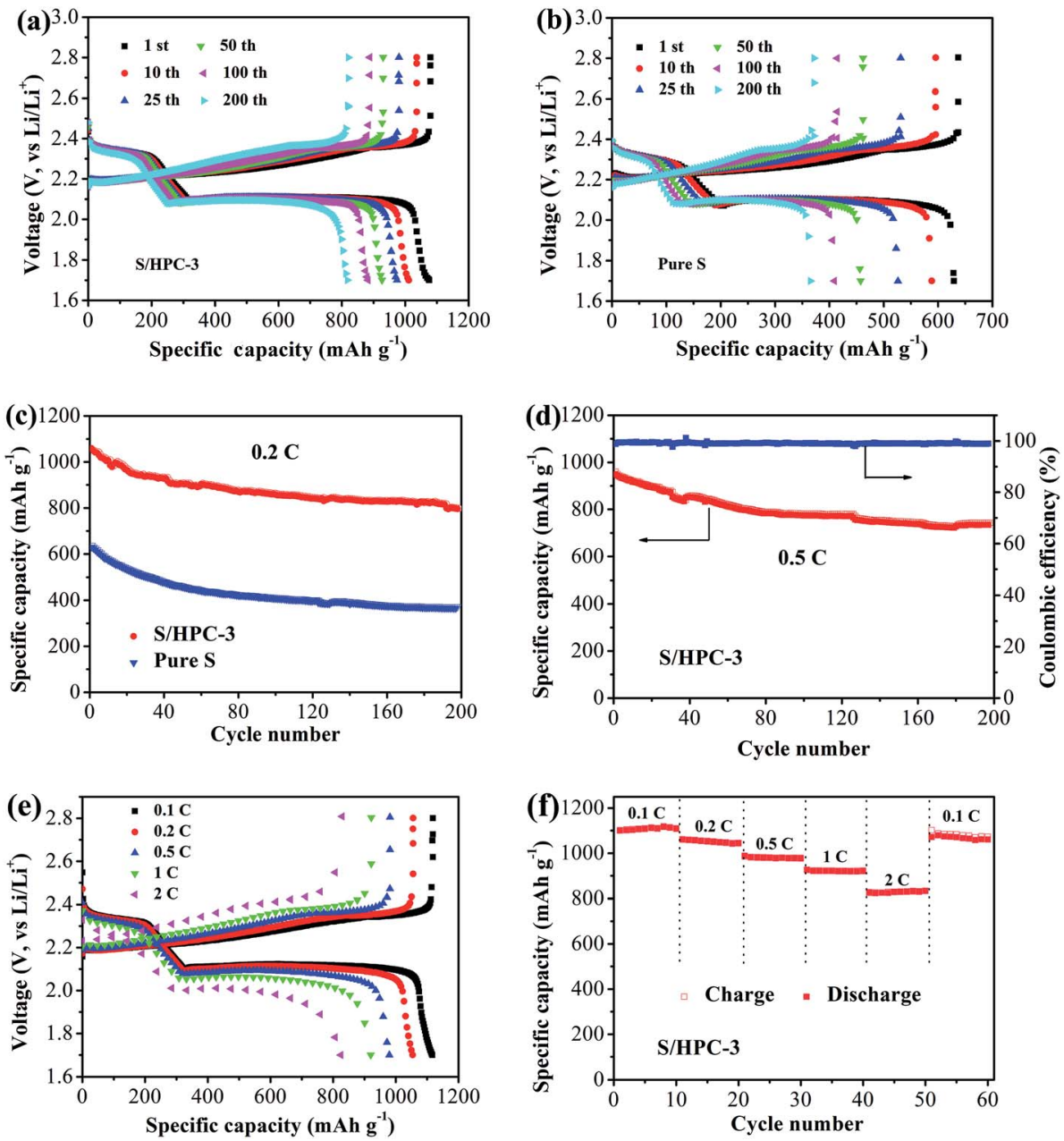

Fig. 9 Galvanostatic charge-discharge curves of (a) S/HPC-3 and (b) pure $\mathrm{S}$ at $0.2 \mathrm{C}$, (c) cycling performances of S/HPC-3 and pure $\mathrm{S}$ at $0.2 \mathrm{C}$, (d) cycling performance of the S/HPC-3 at $0.5 \mathrm{C}$, (e) galvanostatic charge-discharge curves of S/HPC-3 at different current density, and (f) rate performance of S/HPC-3 composite cathode.

performance. The microporous and small mesopore can provide more active sites for electrochemical reaction, and trap sulfur and polysulfide, thereby alleviating the shuttle effect and improving the efficiency and stability. Additionally, threedimensionally interconnected pore structures shorten the transport distance of $\mathrm{Li}^{+}$and electrolyte, which is favorable for high rate capability. (2) High electronic conductivity. The localized graphited-carbon walls and graphite structures offers high electrical conductivity for composite cathode, which is also contribute to the excellent rate capability.

\section{Conclusions}

In this paper, HPC samples with micropores, mesopores and macrospores were synthesized by in situ formation of template in carbon matrix. HPC-3 sample with the highest specific surface area and the largest pore volume can be obtained by adjusting the ratio of trilithium citrate tetrahydrate to sucrose being 2.31:1. The HPC-3 sample consists of threedimensionally interconnected pore structure with graphitedcarbon walls and graphite flakes, which increase the electric conductivity of HPC-3. When encapsulating $61 \%$ sulfur into the HPC-3 host, the obtained S/HPC-3 composite cathode material displayed a high initial capacity of $1059 \mathrm{~mA} \mathrm{~h} \mathrm{~g}^{-1}$ and a stable capacity of $797 \mathrm{~mA} \mathrm{~h} \mathrm{~g}^{-1}$ after 200 cycles, at a current density of $0.2 \mathrm{C}$. Moreover, the S/HPC-3 composite cathode delivered

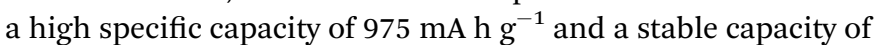
$735 \mathrm{~mA} \mathrm{~h} \mathrm{~g}^{-1}$ after 200 cycles, at a current density of $0.5 \mathrm{C}$. The discharge capacities of S/HPC-3 composite cathode at 0.1, 0.2,

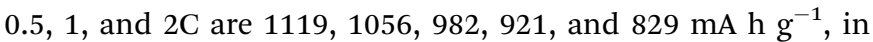
their turns. The excellent electrochemical performance of $\mathrm{S} /$ HPC-3 is attributed to the synergistic advantages of hierarchical porous structure and high electronic conductivity.

\section{Conflicts of interest}

There are no conflicts to declare.

\section{Acknowledgements}

The authors would like to thank the National Natural Science Foundation of China (Grant No. 21643002, 51573215, 21506260, 
21706294); the China Postdoctoral Science Foundation (Grant No. 2016M600697); Link Project of the National Natural Science Foundation of China and Guangdong Province (Grant No. U1301244); Guangdong Province Sci \& Tech Bureau Key Strategic Project (Grant No. 2016B010114004, 2017B090901003); Guangdong Natural Science Foundation (Grant No. 2014A030313159, 2016A030313354); Guangzhou Scientific and Technological Planning Project (Grant No. 2014J4500002, 201607010042); and the Fundamental Research Funds for the Central Universities (Grant No. 171gjc37) for financial support of this work.

\section{References}

1 M. S. Whittingham, Chem. Rev., 2004, 104, 4271-4302.

2 S. K. Liu, K. Xie, Y. J. Li, Z. X. Chen, X. B. Hong, L. J. Zhou, J. F. Yuan and C. M. Zheng, Rsc Adv, 2015, 5, 5516-5522.

3 P. Strubel, S. Thieme, T. Biemelt, A. Helmer, M. Oschatz, J. Bruckner, H. Althues and S. Kaskel, Adv. Funct. Mater., 2015, 25, 287-297.

4 P. G. Bruce, S. A. Freunberger, L. J. Hardwick and J.-M. Tarascon, Nat. Mater., 2012, 11, 19-29.

5 D. Peramunage and S. Licht, Science, 1993, 261, 1029-1032. 6 X. Ji and L. F. Nazar, J. Mater. Chem., 2010, 20, 9821-9826.

7 X. Ji, S. Evers, R. Black and L. F. Nazar, Nat. Commun., 2011, 2, 325.

8 B. Zhang, S. J. Wang, M. Xiao, D. M. Han, S. Q. Song, G. H. Chen and Y. Z. Meng, RSC Adv., 2015, 5, 38792-38800.

9 Y. Yang, G. Zheng and Y. Cui, Chem. Soc. Rev., 2013, 42, 30183032.

10 J. A. Dean, Lange's Handbook of Chemistry, McGraw-Hill Professional, New York, 1985, pp. 3-5.

11 A. Manthiram, Y. Fu, S.-H. Chung, C. Zu and Y.-S. Su, Chem. Rev., 2014, 114, 11751-11787.

12 S.-E. Cheon, K.-S. Ko, J.-H. Cho, S.-W. Kim, E.-Y. Chin and H.-T. Kim, J. Electrochem. Soc., 2003, 150, A796-A799.

13 R. D. Rauh, K. M. Abraham, G. F. Pearson, J. K. Surprenant and S. B. Brummer, J. Electrochem. Soc., 1979, 126, 523-527.

14 X. Tao, X. Chen, Y. Xia, H. Huang, Y. Gan, R. Wu, F. Chen and W. Zhang, J. Mater. Chem. A, 2013, 1, 3295-3301.

15 M. R. Wang, H. M. Zhang, Y. N. Zhang, J. Li, F. X. Zhang and W. Hu, J. Solid State Electrochem., 2013, 17, 2243-2250.

16 X. Li, Y. Cao, W. Qi, L. V. Saraf, J. Xiao, Z. Nie, J. Mietek, J.-G. Zhang, B. Schwenzer and J. Liu, J. Mater. Chem., 2011, 21, 16603-16610.

17 B. Zhang, X. Qin, G. R. Li and X. P. Gao, Energy Environ. Sci., 2010, 3, 1531-1537.

18 X. L. Ji, K. T. Lee and L. F. Nazar, Nat. Mater., 2009, 8, 500506.

19 Y.-S. Su, Y. Fu and A. Manthiram, Phys. Chem. Chem. Phys., 2012, 14, 14495-14499.

20 J. Guo, Y. Xu and C. Wang, Nano Lett., 2011, 11, 4288-4294.

21 W. Wei, J. Wang, L. Zhou, J. Yang, B. Schumann and Y. Nuli, Electrochem. Commun., 2011, 13, 399-402.

22 G. Zheng, Y. Yang, J. J. Cha, S. S. Hong and Y. Cui, Nano Lett., 2011, 11, 4462-4467.
23 L. Ji, M. Rao, S. Aloni, L. Wang, E. J. Cairns and Y. Zhang, Energy Environ. Sci., 2011, 4, 5053-5059.

24 J. Shan, Y. Liu, Y. Su, P. Liu, X. Zhuang, D. Wu, F. Zhang and X. Feng, J. Mater. Chem. A, 2016, 4, 314-320.

25 J. Z. Wang, L. Lu, M. Choucair, J. A. Stride, X. Xu and H.-K. Liu, J. Power Sources, 2011, 196, 7030-7034.

26 Y. Cao, X. Li, I. A. Aksay, J. Lemmon, Z. Nie, Z. Yang and J. Liu, Phys. Chem. Chem. Phys., 2011, 13, 7660-7665.

27 M. Xiao, M. Huang, S. S. Zeng, D. M. Han, S. J. Wang, L. Y. Sun and Y. Z. Meng, RSC Adv., 2013, 3, 4914-4916.

28 D. M. Han, B. Zhang, M. Xiao, P. K. Shen, S. J. Wang, G. H. Chen and Y. Z. Meng, Int. J. Hydrogen Energy, 2014, 39, 16067-16072.

29 J. Wang, J. Chen, K. Konstantinov, L. Zhao, S. H. Ng, G. X. Wang, Z. P. Guo and H. K. Liu, Electrochim. Acta, 2006, 51, 4634-4638.

30 Y. Fu and A. Manthiram, J. Phys. Chem. C, 2012, 116, 89108915.

31 X.-G. Yu, J.-Y. Xie, J. Yang, H.-J. Huang, K. Wang and Z.-S. Wen, J. Electroanal. Chem., 2004, 573, 121-128.

32 J. Fanous, M. Wegner, J. Grimminger, Ä. Andresen and M. R. Buchmeiser, Chem. Mater., 2011, 23, 5024-5028.

33 W. Zhou, Y. Yu, H. Chen, F. J. DiSalvo and H. D. Abruña, J. Am. Chem. Soc., 2013, 135, 16736-16743.

34 L. Xiao, Y. Cao, J. Xiao, B. Schwenzer, M. H. Engelhard, L. V. Saraf, Z. Nie, G. J. Exarhos and J. Liu, J. Mater. Chem. A, 2013, 1, 9517-9526.

35 S. Evers, T. Yim and L. F. Nazar, J. Phys. Chem. C, 2012, 116, 19653-19658.

36 B. Ding, C. Z. Yuan, L. F. Shen, G. Y. Xu, P. Nie and X. G. Zhang, Chem.-Eur. J., 2013, 19, 1013-1019.

37 S. Dutta, A. Bhaumik and K. C. W. Wu, Energy Environ. Sci., 2014, 7, 3574-3592.

38 B. Xu, L. Peng, G. Q. Wang, G. P. Cao and F. Wu, Carbon, 2010, 48, 2377-2380.

39 C. R. Zhao, W. K. Wang, Z. B. Yu, H. Zhang, A. B. Wang and Y. S. Yang, J. Mater. Chem., 2010, 20, 976-980.

40 G. Y. Xu, B. Ding, P. Nie, L. F. Shen, H. Dou and X. G. Zhang, ACS Appl. Mater. Interfaces, 2014, 6, 194-199.

41 D. X. Wang, A. P. Fu, H. L. Li, Y. Q. Wang, P. Z. Guo, J. Q. Liu and X. S. Zhao, J. Power Sources, 2015, 285, 469-477.

42 C. Tang, B. Q. Li, Q. Zhang, L. Zhu, H. F. Wang, J. L. Shi and F. Wei, Adv. Funct. Mater., 2016, 26, 577-585.

43 Z. J. Zhang, H. T. Yi and X. Y. Chen, J. Alloys Compd., 2015, 651, 414-422.

44 J. J. Kim, H. S. Kim, J. Ahn, K. J. Lee, W. C. Yoo and Y. E. Sung, J. Power Sources, 2016, 306, 617-622.

45 S. C. Wei, H. Zhang, Y. Q. Huang, W. K. Wang, Y. Z. Xia and Z. B. Yu, Energy Environ. Sci., 2011, 4, 736-740.

46 D. S. Jung, T. H. Hwang, J. H. Lee, H. Y. Koo, R. A. Shakoor, R. Kahraman, Y. N. Jo, M. S. Park and J. W. Choi, Nano Lett., 2014, 14, 4418-4425.

47 C. Xu, Y. Wu, X. Zhao, X. Wang, G. Du, J. Zhang and J. Tu, J. Power Sources, 2015, 275, 22-25.

48 M. Klose, K. Pinkert, M. Zier, M. Uhlemann, F. Wolke, T. Jaumann, P. Jehnichen, D. Wadewitz, S. Oswald, J. Eckert and L. Giebeler, Carbon, 2014, 79, 302-309. 
49 X. Y. Tao, X. R. Chen, Y. Xia, H. Huang, Y. P. Gan, R. Wu, F. Chen and W. K. Zhang, J. Mater. Chem. A, 2013, 1, 32953301.

50 H. Huang, Y. Xia, X. Tao, J. Du, J. Fang, Y. Gan and W. Zhang, J. Mater. Chem., 2012, 22, 10452-10456.

51 X. Yang, L. Zhang, F. Zhang, Y. Huang and Y. Chen, ACS Nano, 2014, 8, 5208-5215.

52 F. Chen, J. Yang, T. Bai, B. Long and X. Y. Zhou, Electrochim. Acta, 2016, 192, 99-109.

53 M. R. Wang, H. Z. Zhang, W. Zhou, X. F. Yang, X. F. Li and H. M. Zhang, J. Mater. Chem. A, 2016, 4, 1653-1662.
54 F.-F. Zhang, G. Huang, X.-X. Wang, Y.-L. Qin, X.-C. Du, D.-M. Yin, F. Liang and L.-M. Wang, Chem.-Eur. J., 2014, 20, 17523-17529.

55 L. Zhu, H. J. Peng, J. Y. Liang, J. Q. Huang, C. M. Chen, X. F. Guo, W. C. Zhu, P. Li and Q. Zhang, Nano Energy, 2015, 11, 746-755.

56 Y. Xia, W. K. Zhang, Z. Xiao, H. Huang, H. J. Zeng, X. R. Chen, F. Chen, Y. P. Gan and X. Y. Tao, J. Mater. Chem., 2012, 22, 9209-9215. 